\title{
HHV-8 infection in patients with AIDS-related Kaposi's sarcoma in Brazil
}

R. Keller ${ }^{1}$, A. Zago ${ }^{1,2}$, M.C. Viana' ${ }^{1}$ D. Bourboulia ${ }^{3}$, C. D esgranges ${ }^{4}$, J. Casseb ${ }^{5}$, W.V. Moura ${ }^{6}$, R. Dietze ${ }^{1}$ and H. Collandre?

\author{
${ }^{1} N$ úcleo de Doenças Infecciosas, U niversidade Federal do Espírito Santo, and \\ ${ }^{2}$ Centro de Referência DST/AIDS, Vitória, ES, Brasil \\ ${ }^{3}$ Department of Molecular Pathology and O ncology, W indeyer Institute, \\ University College London, London, UK \\ ${ }^{4}$ U 271 INSERM, 151 Lyon, France \\ ${ }^{5}$ Centro de Referência DST/AIDS, São Paulo, SP, Brasil \\ ${ }^{6}$ Hospital Santa Rita, Vitória, ES, Brasil \\ ${ }^{7}$ Institut Pasteur, Unité d'O ncologie Virale, CNRS U RA 1930, Paris, France
}

\section{Correspondence \\ R. Keller \\ Rua Goiânia, 22 \\ Itapoã \\ 29101-780 Vila Velha, ES \\ Brasil \\ Fax: + 55-27-335-2857 \\ E-mail: kellygtr@ npd.ufes.br \\ Research supported by FACITEC \\ (Fundo de Apoio à Ciência e \\ Tecnologia do Município de Vitória, ES, Brazil), CAPES, CNPq and CNRS \\ (Centre National de la Recherche \\ Scientifique). Publication supported by FAPESP.}

The present address of M.C. Viana is Departamento de Medicina Social, Escola de Medicina da Santa Casa de Misericórdia de Vitória (EM ESCAM), Vitória, ES, Brasil.

Received July 26, 2000 Accepted April 2, 2001

\section{Abstract}

The aims of the present study were to determine the prevalence of human herpesvirus type 8 (HHV-8) in HIV-positive Brazilian patients with $(\mathrm{HIV}+/ \mathrm{KS}+)$ and without Kaposi's sarcoma (HIV+/KS-) using PCR and immunofluorescence assays, to assess its association with KS disease, to evaluate the performance of these tests in detecting $\mathrm{HHV}-8$ infection, and to investigate the association between antiHHV -8 antibody titers, CD4 counts and staging of KS disease. Blood samples from 66 patients, $39 \mathrm{HIV}+/ \mathrm{KS}+$ and $27 \mathrm{HIV}+/ \mathrm{KS}-$, were analyzed for $\mathrm{HHV}-8$ viremia in peripheral blood mononuclear cells by PCR and HHV-8 antigenemia for latent and lytic infection by immunofluorescence assay. Positive samples for latent nuclear HHV-8 antigen (LNA) antibodies were titrated out from $1 / 100$ to $1 / 409,600$ dilution. Clinical information was collected from medical records and risk behavior was assessed through an interview. HHV-8 DNA sequences were detected by PCR in $74.3 \%$ of $\mathrm{KS}+$ patients and in $3.7 \%$ of KS- patients. Serological assays were similar in detecting anti-LNA antibodies and anti-lytic antigens in sera from $\mathrm{KS}+$ patients $(79.5 \%)$ and KS- patients (18.5\%). HHV-8 was associated with KS whatever the method used, i.e., PCR (odds ratio $(\mathrm{OR})=7.4,95 \%$ confidence interval $(\mathrm{CI})=2.16-25.61)$ or anti-LNA and anti-lytic antibodies (OR $=17.0,95 \% \mathrm{CI}=4.91-59.14)$. Among $\mathrm{KS}+$ patients, $\mathrm{HHV}-8$ titration levels correlated positively with CD4 counts (rho $0.48, \mathrm{P}=0.02$ ), but not with KS staging. HHV-8 is involved in the development of KS in different geographic areas worldwide, as it is in Brazil, where HHV8 is more frequent among HIV+ patients. KS severity was associated with immunodeficiency, but no correlation was found between HHV8 antibody titers and KS staging.
Key words

- AIDS-related Kaposi's sarcoma

- Human herpesvirus type 8

- HHV-8

- Brazil 


\section{Introduction}

Kaposi's sarcoma-associated herpesvirus (KSHV) or human herpesvirus type 8 (HHV8 ) has been frequently detected in lesions and peripheral blood mononuclear cells (PBMC) from patients with all forms of Kaposi's sarcoma (KS) disease $(1,2)$, as well as in specific types of AIDS-associated lymphomas $(3,4)$. The prevalence of HHV-8 in the general population is low, and many studies have suggested that there is a close association between HHV-8 and KS (1,5-8). HHV-8 is frequently detected in KS-positive patients with and without HIV infection in Africa $(9,10)$ and in other areas where KS is endemic, such as Mediterranean and eastern European countries (9). In western countries where KS is predominantly associated with HIV infection, HHV-8 is frequently detected in patients with AIDS-related KS $(1,5,6,11$, 12), though it has also been found in HIVnegative patients with KS, and in healthy individuals the infection is not common (1315).

In Brazil, the prevalence of HHV-8 is not well established. Some studies have shown that HHV-8 infection is associated with KS, male gender, homosexual orientation and HIV and hepatitis B virus infection $(8,15)$. Recently, however, immunofluorescence studies identified a new subtype of HHV-8, subtype $\mathrm{E}$, detected in different tribes of Brazilian Amerindians in the north region of Brazil. HIV or KS disease was not identified in these populations and the transmission of HHV-8 seems to be by the oral rather than the sexual route (16).

The present study was devised to determine the prevalence of HHV-8 infection in HIV-positive patients with and without KS, comparing results from PCR and two serological assays, and also to evaluate its association with KS disease. The correlation between antibody titers and the different stages of KS disease, as well as with the number of CD4 cells, was investigated.

\section{Material and Methods}

\section{Description of the study and sample composition}

A cross-sectional study was conducted from January 1997 to February 1998 at two STD/AIDS clinics in Vitória and São Paulo, by examining two groups of HIV-positive patients. The first group consisted of all patients aged 18 and above diagnosed with KS (KS group) confirmed by histological examination who were attending the clinics for follow-up during the study period. A total of 39 patients out of 40 patients selected (refusal rate was $2.5 \%$ ) agreed to participate. The second group was formed by 27 HIV-seropositive patients aged 18 and above without KS or any clinical indication of KS, who were randomly selected from the same clinics, also attending follow-up consultations. Although the HIV serostatus of all patients was already known, they were retested by ELISA (Abbott do Brasil, São Paulo, SP, Brazil and Organon Teknika, São Paulo, SP, Brazil) and confirmed by immunofluorescence assay (IFA; Fiocruz, Rio de Janeiro, RJ, Brazil), as part of the study protocol. Demographic information and patterns of risk behavior were collected during a structured face-to-face interview. Clinical information, latest CD4 count and HIV viral load were taken from medical records. A blood specimen was collected immediately after the interview in order to perform serological testing and PCR for HHV-8. All patients gave written consent to take part in the study. The protocol was approved by the Ethics Committees of the participating hospitals.

The KS group was further classified according to clinical presentation in terms of number of lesions and organs affected (17): KS stage I corresponded to limited cutaneous lesions ( $<10$ lesions or lesions restricted to one anatomic area); stage II, disseminated cutaneous lesions $(>10$ or in more than one 
anatomic area); stage III, visceral lesions only (gastrointestinal, lymph nodes), and stage IV, cutaneous and visceral lesions.

\section{Laboratory methods}

PBMC were separated from heparinized peripheral blood $(15 \mathrm{ml})$ by Ficol-Hypaque, and DNA was extracted with the QuiAmp blood kit (Quiagen, Chatsworth, CA, USA). After extraction, DNA was stored at $4^{\circ} \mathrm{C}$ until use. Oligonucleotide primers were used to amplify a 233-bp region of the $\mathrm{KS}_{3} 3 \mathrm{O}_{233}$ viral sequence in the DNA samples. A sample of $25 \mu \mathrm{l}$ contained approximately 150-200 ng of genomic DNA, 100 pmol of each primer (5'TCCGTGTTGTCTACGGTCCAG3') and 5'AGCCGAAAGGATTCCACCAT3'), 2 units of Taq polymerase, $100 \mu \mathrm{M}$ of each deoxynucleotide triphosphate, $1.5 \mathrm{mM}$ magnesium chloride and $10 \mathrm{mM}$ Tris-hydrochloride, $\mathrm{pH}$ 9.0. PCR amplification was carried out at $94^{\circ} \mathrm{C}$ for $2 \mathrm{~min}(1 \mathrm{cycle}), 9^{\circ} \mathrm{C}$ for 1 $\min , 58^{\circ} \mathrm{C}$ for $1 \mathrm{~min}$ and $72^{\circ} \mathrm{C}$ for $1.5 \min (35$ cycles), and $72^{\circ} \mathrm{C}$ for $5 \mathrm{~min}$ ( 1 cycle). The amplification products were visualized on $2 \%$ agarose gel containing ethidium bromide and were scored for the presence or absence of the 233-bp DNA fragment. Genomic DNA from BCP-1 cells (HHV-8 positive and Epstein-Bar virus negative) was used as a positive control, and buffer used in the extraction of DNA or water was used as negative control. The DNA of all patients was subjected to more than one PCR cycle to confirm the results.

Southern blot. PCR fragments on the agarose gel were transferred to nylon membranes and submitted to Southern blot hybridization with a 25-bp internal oligonucleotide end-labeled with $\left({ }^{32} \mathrm{P}\right)$ deoxycytidine triphosphate. PCR was considered positive only if PCR products hybridized specifically in the expected 233-bp region.

Immunofluorescence assay. All serum samples were blindly analyzed by indirect IFA for the detection of human IgG antibod- ies against a latent nuclear HHV-8 antigen (LNA-1). Briefly, BCP-1 cells latently infected with HHV-8 were fixed in $4 \%$ paraformaldehyde and permeabilized with $0.2 \%$ Triton X-100. Serum samples diluted (1:100) in PBS with 3\% FBS were incubated with the cells on slides for $45 \mathrm{~min}$ at room temperature and after several washes rabbit antihuman IgG FITC antibody (diluted 1:60) was added for $20 \mathrm{~min}$. The slides were examined by fluorescence microscopy and serum samples were considered IFA positive for anti-LNA-1 antibody if they gave a punctate nuclear pattern in BCP-1 nuclei at 1:100 dilution. All experiments were conducted with positive and negative serum controls. Positive samples were further titrated up to 1/409,600 dilution. To detect lytic antigens, BCP-1 cells were treated with $20 \mathrm{ng} / \mathrm{ml}$ TPA for 4 days to induce replication of HHV-8.

\section{Statistical analysis}

All data collected were coded and stored in a dataset using the Statistical Package for the Social Sciences. Standard descriptive methods were used: mean and standard deviation (SD) for quantitative variables and frequency distribution for qualitative data. Prevalence of HHV-8 and confidence intervals $(\mathrm{CI})$ were determined for each group. The association between HHV-8 and KS was evaluated by the chi-square test with continuity correction. Odds ratios (OR) and CI were also calculated to estimate the magnitude of such association. The Student $t$-test for two independent samples was used to assess mean differences between groups. The agreement between LNA, lytic and PCR test results was assessed by the kappa $(\kappa)$ statistics. Spearman's rho $(\rho)$ correlation coefficient was calculated to evaluate the correlation between HHV-8 anti-LNA titers and stage of KS disease and CD4 counts. A significance level of 0.05 , two-tailed, was used for all tests. 


\section{Results}

\section{Study population}

Sixty-six HIV-1-infected patients were studied, 39 of them KS positive and $27 \mathrm{KS}$

Table 1. Demographic information and risk behavior for HIV infection among HIVseropositive patients with and without Kaposi's sarcoma (KS).

\begin{tabular}{lcc}
\hline & KS positive $(\mathrm{N}=39)$ & KS negative $(\mathrm{N}=27)$ \\
\hline Age in years (mean \pm SD) & $37 \pm 6.31$ & $33.4 \pm 8.3$ \\
Gender - N (\%) & & \\
$\quad$ Male & $38(97.4)$ & $18(66.7)$ \\
Female & $1(2.6)$ & $9(33.3)$ \\
Sexual orientation - N (\%) & & \\
Heterosexual & $7(17.9)$ & $14(51.9)$ \\
Homosexual & $15(38.5)$ & $6(22.2)$ \\
Bisexual & $17(43.6)$ & $7(25.9)$ \\
Use of condoms - N (\%) & & \\
Never & $11(34.3)$ & $3(12.0)$ \\
Sometimes & $7(22.0)$ & $7(26.0)$ \\
Always & $2(6.3)$ & $1(4.0)$ \\
Only after the HIV result & $12(37.5)$ & $14(56.0)$ \\
N.K. & $7(7.6)$ & $2(7.4)$ \\
IDU - N (\%) & $3(7.7)$ & $6(22.2)$ \\
\hline
\end{tabular}

N.K. = not known, IDU = intravenous drug users.

Table 2. Patients' clinical and laboratory information.

\begin{tabular}{lcc}
\hline & $\begin{array}{c}\text { KS positive } \\
(\mathrm{N}=39)\end{array}$ & $\begin{array}{c}\text { KS negative } \\
(\mathrm{N}=27)\end{array}$ \\
\hline HIV infection in months (mean \pm SD) & $60.9 \pm 38.88$ & $44.9 \pm 24.29$ \\
KS diagnosis in months (mean \pm SD) & $25.9 \pm 15.89$ & - \\
AIDS diagnosis - N (\%) & $39(100.0)$ & $13(48.1)$ \\
Antiretroviral therapy use - N (\%) & $38(97.4)$ & $19(70.4)$ \\
Opportunistic infections - N (\%) & $32(82.1)$ & $11(40.7)$ \\
Oropharyngeal candidiasis & $17(45.9)$ & $12(44.4)$ \\
Mycobacterium tuberculosis & $16(42.1)$ & $3(11.1)$ \\
Pneumocystis carinii pneumonia & $8(21.6)$ & $2(7.4)$ \\
Toxoplasmosis of the brain & $6(16.2)$ & $1(3.7)$ \\
Cytomegalovirus disease & $6(16.2)$ & $2(7.4)$ \\
Herpes zoster & $7(18.9)$ & $11(40.7)$ \\
Other opportunistic infections & $5(12.8)$ & $436.35 \pm 331.61$ \\
CD4 counts (mean \pm SD) & $171.97 \pm 164.09$ & \\
HIV viral load (mean \pm SD) & $149378.65 \pm 251667.02$ & $118972.73 \pm 314130.37$ \\
\hline KS = Kaposi's sarcoma. & & \\
& &
\end{tabular}

negative. Both groups were mainly composed of single young men (Table 1). Regarding risk behaviors for HIV infection (Table 1), a higher frequency of men with homosexual contact was observed in the KSpositive group compared to the KS-negative group $(\mathrm{P}=0.008)$. Unprotected sex was frequently observed in both groups. Although use of condoms after HIV seropositivity was more commonly reported by KS-negative patients, the difference was not statistically significant $(\mathrm{P}=0.2)$.

Clinical information is shown in Table 2. All KS patients presented cutaneous lesions. Four (10.3\%) of them were classified as KS stage I, $14(35.9 \%)$ as stage II, and 21 (53.8\%) patients were in KS stage IV. KS was the AIDS-defining illness in 25 patients (64.1\%); of these, the diagnosis of KS and HIV was made at the same time in $13(52.0 \%)$ patients, and for the remaining $12(48.0 \%)$ the mean time since HIV seropositivity was 4.4 years (SD 2.9). In $12(30.8 \%)$ patients the onset of KS occurred about 10 months (SD 4.2) after the diagnosis of AIDS, and for 2 patients such data were not available. Among the opportunistic infections, oropharyngeal candidiasis and tuberculosis were the most common in both groups. There was no difference between groups regarding HIV viral load $(\mathrm{P}=0.72, t$-test $)$. However, CD4 counts were significantly lower among KS-positive patients $(\mathrm{P}=0.001, t$-test $)$.

\section{HHV-8 prevalence}

The presence of HHV-8 infection was assessed by PCR, anti-LNA IFA and antilytic IFA. The yield prevalence rates and respective confidence intervals are presented in Table 3. Using PCR, 74.4\% (29/39) of the KS-positive patients and $3.7 \%(1 / 27)$ of the KS-negative patients were positive for the KS330 sequence. LNA and lytic assays detected the same number of HHV-8-positive patients in each group, $31(79.5 \%)$ in the KSpositive group and $5(18.5 \%)$ in the KS- 
negative group; of these, $24(77.4 \%)$ and 3 (60.0\%), respectively, were detected by both antigens. Thirty-eight $(97.4 \%)$ of the KS patients were found to be HHV-8 seropositive by both serological tests.

\section{Performance of and agreement between the HHV-8 detection tests}

The results obtained with each test were compared and are shown in Table 4. The agreement between LNA and lytic tests was $73 \%(\kappa=0.450, \mathrm{P}=0.000)$ and the agreement between LNA or lytic test and PCR was $76 \%(\kappa=0.519, \mathrm{P}=0.000)$. All patients who were HHV-8 positive by PCR were also positive for one or both serological tests. When patients were stratified by CD 4 count, the agreement between tests was significantly higher for those with less severe immunodeficiency $\left(\mathrm{CD} 4>200\right.$ cells $\left./ \mathrm{mm}^{3}\right)$.

\section{Association between HHV-8 and KS}

The association between HHV-8 and KS was examined. Whatever the method used to detect HHV-8 in the KS-positive and KSnegative groups, a strong association with KS disease was observed (PCR: OR $=7.4$, $95 \% \mathrm{CI}=2.16-25.61$; anti-LNA and antilytic antibodies: $\mathrm{OR}=17.0,95 \% \mathrm{CI}=4.91$ 59.14).

\section{Association between KS staging, anti-LNA antibodies and immunodeficiency}

When considering all HHV-8-positive patients with and without KS, no correlation was observed between the magnitude of antiLNA antibody titers and CD4 counts (Spearman's $\rho=0.28, P=0.16$ ). However, among the HHV-8-positive patients who were KS positive, titration levels correlated positively with CD4 counts $(\rho=0.48, P=0.02)$, but not with KS staging $(\rho=-0.18, P=0.34)$.

We also investigated if immunodeficiency of patients was associated with KS severity
(Table 5). We observed that CD4 cell counts decreased with increasing disease severity (KS stage I to KS stage IV), showing a correlation between immunodeficiency and KS progression $(\rho=-0.42, P=0.025)$. No correlation was found between KS staging and anti-LNA titers $(\rho=0.048, P=0.78)$.

Table 3. Prevalence rates of HHV-8 infection: comparison of assays.

\begin{tabular}{lcc}
\hline $\begin{array}{l}\text { Assays } \\
\text { (HHV-8-positive result) }\end{array}$ & $\begin{array}{c}\text { KS positive }(\mathrm{N}=39) \\
\mathrm{N}(\%, 95 \% \mathrm{Cl})\end{array}$ & $\begin{array}{c}\text { KS negative }(\mathrm{N}=27) \\
\mathrm{N}(\%, 95 \% \mathrm{Cl})\end{array}$ \\
\hline PCR & $29(74.3,60.6-88.1)$ & $1(3.7,0-10.8)$ \\
Anti-latent IFA & $31(79.5,66.8-92.2)$ & $5(18.5,3.9-33.2)$ \\
Anti-lytic IFA & $31(79.5,66.8-92.2)$ & $5(18.5,3.9-33.2)$ \\
PCR and anti-latent & $24(61.5,46.3-76.8)$ & $1(3.7,0-10.8)$ \\
PCR and anti-lytic & $24(61.5,46.3-76.8)$ & $1(3.7,0-10.8)$ \\
Anti-lytic and anti-latent & $24(61.5,46.3-76.8)$ & $3(11.1,0-23.0)$ \\
PCR and anti-lytic and anti-latent & $20(51.3,35.6-67.0)$ & $1(3.7,0-10.8)$ \\
Positive by at least one & $38(97.4,92.5-100)$ & $7(25.9,9.4-42.5)$ \\
$\quad$ serological method & & \\
Negative by all methods & $1(2.6,0-7.5)$ & $20(74.1,57.5-90.6)$ \\
\hline
\end{tabular}

$\mathrm{PCR}=$ polymerase chain reaction, IFA = immunofluorescence assay, KS = Kaposi's sarcoma.

Table 4. Agreement between tests in relation to immunodeficiency status.

\begin{tabular}{|c|c|c|c|c|c|c|}
\hline \multirow[t]{2}{*}{ Tests } & \multicolumn{2}{|c|}{ All patients } & \multicolumn{2}{|c|}{$\begin{array}{l}\text { Patients with CD4 } \\
\leq 200 \text { cells } / \mathrm{mm}^{3}\end{array}$} & \multicolumn{2}{|c|}{$\begin{array}{l}\text { Patients with CD4 } \\
>200 \text { cells } / \mathrm{mm}^{3}\end{array}$} \\
\hline & kappa & $P$ value & kappa & $P$ value & kappa & $P$ value \\
\hline PCR vs LNA & 0.519 & 0.000 & 0.292 & 0.161 & 0.659 & 0.000 \\
\hline PCR vs Iytic & 0.519 & 0.000 & 0.553 & 0.008 & 0.501 & 0.006 \\
\hline LNA vs lytic & 0.450 & 0.000 & 0.195 & 0.349 & 0.588 & 0.001 \\
\hline
\end{tabular}

$\mathrm{PCR}=$ polymerase chain reaction, $\mathrm{LNA}=$ immunofluorescence assay for latent nuclear HHV-8 antigens, lytic = immunofluorescence assay for lytic HHV-8 antigens.

Table 5. Kaposi's sarcoma (KS) status, CD4 counts and anti-LNA antibody titers of HHV8-positive patients.

\begin{tabular}{lcc}
\hline KS status & CD4 counts & Anti-LNA titers \\
\hline KS negative $(\mathrm{N}=7)$ & $409.29 \pm 283.85$ & $2771.43 \pm 4665.02$ \\
KS I $(\mathrm{N}=4)$ & $258.67 \pm 254.24$ & $54375.00 \pm 100194.3$ \\
KS II $(\mathrm{N}=14)$ & $212.91 \pm 188.99$ & $58978.57 \pm 107152.30$ \\
KS III $(\mathrm{N}=0)$ & - & - \\
KS IV $(\mathrm{N}=20)$ & $127.50 \pm 121.23$ & $27970.00 \pm 52346.01$
\end{tabular}

Data are reported as means \pm SD. 


\section{Discussion}

Many studies have shown that infection with HHV-8 is strongly associated with the development of KS (1,5-7). They have examined HHV-8 DNA extracted from lesions, PBMC and other sites in HIV-positive and -negative patients, as well as in healthy people. In the present study, such association was also observed when we looked for HHV-8 DNA sequences in PBMC and antiLNA and anti-lytic antibodies in the serum of HIV-positive patients with KS with various levels of disease severity and in patients without KS.

Our findings showed that the prevalence of HHV-8 in HIV-positive patients with or without KS was high: $97.4 \%$ of KS-positive patients and $26 \%$ of the KS-negative patients were positive for HHV-8 in at least one serological test. Among the three methods used, PCR produced less positive results than both serological methods, a pattern that has been frequently observed in other studies $(5,6,18)$. HHV-8 DNA sequences are detected by PCR in almost $100 \%$ of tumor lesions of KS patients. In PBMC, however, the frequency of HHV-8 detection is variable, ranging from 50 to $93 \%$ in different geographic regions and different populations (16,18-23). In the present study, 29 (75\%) HIV-positive patients with KS and only 1 $(3.7 \%)$ in the KS-negative group were found to be HHV-8 positive by PCR, while 31 $(79.5 \%)$ and $5(18.5 \%)$, respectively, were detected by the serological tests. All patients that were PCR positive were also positive when tested by the serological methods. Our results, in agreement with other studies $(14,18)$, showed that the currently available serological tests are not able to detect individually all positive patients, and more than one test is needed to achieve the best results (Table 3).

Agreement between assays for the detection of HHV-8 antibodies has been limited, in part because assays have not been con- ducted in a standardized fashion, but also because they identify different antigens or antibodies expressed at different times during the viral cycle. When analyzing all patients (KS positive and KS negative) the concordance between the tests was higher between LNA or lytic tests and PCR than between LNA and lytic tests (76 and 73\%, respectively). However, when patients were grouped according to their CD4 counts, the agreement between tests was better in the group with CD4 $>200$ cells $/ \mathrm{mm}^{3}$ than in the group of patients with lower CD4 counts. It is not known whether HHV-8 antibody production is affected by immunosuppression in these patients, but these results suggest that if serum is tested with only one type of antigen or antibody, not all infected persons shall be identified.

To verify if anti-LNA antibody titers and CD4 counts could be related to the severity of KS disease, patients were classified into groups according to the location and number of lesions. As expected, CD4 counts decreased from KS-negative patients to KSpositive stage IV patients. However, the titers in the different groups ranged from 1:100 to $1: 204,800$ and did not fully correlate with the stage or the length of KS disease. One patient with KS lesions in the skin and mouth (subgroup KS IV) had negative results in all three assays. This patient was a 27 -year-old heterosexual man, who had been diagnosed with KS for 4 months and with HIV infection for 18 months. Except in one case, patients with the shortest times of KS disease $(<1$ year) showed the lowest anti-LNA titers independently of their KS stage. All these patients had CD4 counts under 200 cells/ $\mathrm{mm}^{3}$, showing that immune suppression was an important factor for the development of $\mathrm{KS}$, but not for the progression to severe disease. Min and Katzenstein (24) reported similar results showing that HIV-positive patients with KS had lower CD4 counts and higher HIV RNA load than HIV-positive patients without KS. 
In the KS-negative group, HHV-8 antibody titers were lower than in KS-positive patients. Five samples (18.5\%) showed an anti-HHV-8 antibody titer ranging from 1:100 to $1: 12,800$. These findings express the prevalence of the virus in the population attending STD clinics, but this rate is higher than that found in Brazil among HIV-negative/KSnegative individuals $(3.7 \%)$ and blood donors $(4.6 \%)(8)$. Two of the 5 samples showed low anti-LNA antibody titers and were negative by both lytic IFA and PCR and the other 3 were positive by PCR or lytic antibodies. These HHV-8-positive/KS-negative patients will be followed up to check if the antibody titers are predictive of $\mathrm{KS}$, as previously shown by other investigators $(25,26)$.

Our findings show that HHV-8 infection is strongly associated with $\mathrm{KS}$ in HIV-positive Brazilian patients, in agreement with previous reports $(1,5,8,11)$. Using a combination of PCR and IFA, a high prevalence of
HHV-8 was observed both in patients with KS (97\%) and without KS (26\%). None of the tests used was able to individually detect HHV-8 in all patients who tested HHV-8 positive. Although we did not find any association between the serological results of HHV-8 infection and the severity of KS disease, immunity expressed by CD4 counts was an important factor associated with the development of KS. Longitudinal studies with KS-negative patients presenting HHV8 antibodies will be needed to better understand the role of HHV-8 in the pathogenesis of KS disease.

\section{Acknowledgments}

We thank Patrick Moore for the BCP-1 cells and Claudine Buffet Janvresse and Fausto Edmundo Lima Pereira for a critical reading of the manuscript.

\section{References}

1. Chang Y, Cesarman E, Pessin MS, Lee F, Culpepper J , Knowles DM \& Moore PS (1994). Identification of herpesvirus-like DNA sequences in AIDS-associated Kaposi's sarcoma. Science, 266: 1865-1869.

2. Schalling $M$, Ekman $M$, Kaaya EE, Linde $A$ \& Biberfeld P (1995). A role for a new herpes virus (KSHV) in different forms of Kaposi's sarcoma. Nature Medicine, 1: 707-708.

3. Cesarman E, Chang Y, Moore PS, Said J W \& Knowles DM (1995). Kaposi's sarcoma-associated herpesvirus-like DNA sequences in AIDS-related body-cavitybased lymphomas. New England J oumal of Medicine, 332: 1186-1191.

4. Soulier J, Grollet L, Oksenhendler E, Cacoub P, Cazals-Hatem D, Babinet P, d'Agay MF, Clauvel J P, Raphael M, Degos L \& Sigaux J (1995). Kaposi's sarcomaassociated-like DNA sequences in multicentric Castleman's disease. Blood, 86: 1276-1280.

5. Whitby D, Howard MR, Tenant-Flowers M, Brink NS, Copas A, Boshoff C, Hatzioannou T, Suggett FE, Aldam DM, Denton AS, Miller RF, Weller IVD, Weiss
RA, Tedder RS \& Schulz TF (1995). Detection of Kaposi's sarcoma associated herpesvirus in peripheral blood of HIV-infected individuals and progression to Kaposi's sarcoma. Lancet, 346: 799-802.

6. Moore PS, Kingsley LA, Holmberg SD, Spira T, Gupta P, Hoover DR, Parry JP, Conley LJ , J affe HW \& Chang Y (1996). KSHV infection prior to onset of Kaposi's sarcoma. AIDS, 10: 175-180.

7. Boshoff C, Whitby D, Hatzioannou T, Fisher C, van Der Walt J, Hatzakis A, Weiss RA \& Schulz TF (1995). Kaposi's sarcoma-associated herpesvirus in HIVnegative Kaposi's sarcoma. Lancet, 345 : 1043-1044.

8. Zago A, Bourboulia D, Viana MC, Collandre $H$, Dietze R, Boshoff $C \&$ Keller R (2000). The seroprevalence of HHV-8 in Brazil. Sexually Transmitted Diseases, 27: 468-472.

9. Gao SJ, Kingsley L, Li M, Zheng W, Parravicini C, Ziegler J , Newton R, Rinaldo CR, Saah A, Phair J, Detels R, Chang Y \& Moore PS (1996). KSHV antibodies among Americans, Italians and Ugandans with and without Kaposi's sarcoma. Nature
Medicine, 2: 925-928.

10. Chang $Y$, Ziegler J , Wabinga $H$, KatangoleM bidde E, Boshoff C, Schulz TF, Whitby D, Maddalena D, J affe HW, Weiss RA \& M oore PS (1996). Kaposi's sarcoma-associated herpesvirus and Kaposi's sarcoma in Africa. Archives of Internal Medicine, 156: 202-204.

11. Moore PS \& Chang Y (1995). Detection of herpesvirus-like DNA sequences in $\mathrm{Ka}$ posi's sarcoma in patients with and without HIV infection. New England J ournal of Medicine, 332: 1181-1185.

12. Collandre H, Ferris S, Grau O, Montagnier L \& Blanchard A (1995). Kaposi's sarcoma and new herpesvirus. Lancet, 345: 1043.

13. Ambroziak J A, Blackbourn DJ, Herndier BG, Glogau RG, GullettJ H, M CDonald AR, Lennette ET \& Levy J A (1995). Herpeslike sequences in HIV-infected and uninfected Kaposi's sarcoma patients. Science, 268: 582-583.

14. Rabkin CS, SchulzTF, Whitby D, Lennette ET, Magpantay LI, Chatlynne L \& Biggar RJ (1998). Interassay correlation of human herpesvirus 8 serologic tests. J ournal of Infectious Diseases, 178: 304-309. 
15. Caterino-de-Araujo A, Calabro ML, de los Santos-Fortuna E, Suleiman J \& ChiecoBianchi L (1999). Searching for human herpesvirus 8 antibodies in serum samples from patients infected with human immunodeficiency virus type 1 and blood donors. J ournal of Infectious Diseases, 179: 1591-1592.

16. Biggar RJ , Whitby D, Marshall V, Linhares AC \& Black F (2000). Human herpesvirus 8 in Brazilian Amerindians: A hyperendemic population with a new subtype. J ournal of Infectious Diseases, 181: 15621568.

17. Mitsuyasu RT \& Groopman J E (1984). Biology and therapy of Kaposi's sarcoma. Seminars in Oncology, 11: 53-59.

18. Spira TJ , Lam L, Dollard SC, Meng Y, Pau CP, Black J B, Burns D, Cooper B, Hamid M, Huong J , Powell K \& Pellet PE (2000). Comparison of serological assays and PCR for diagnosis of human herpesvirus 8 infection. J ournal of Clinical Microbiology, 38: 2174-2180.

19. Zhang $X$, Fitzpatrick L, Campbell TB, Badaro $R$, Schechter $M$, Melo $M$, Brites C, Pedral-Sampaio D \& Schooley RT (1998). Comparison of the prevalence of antibodies to human herpesvirus 8 (Kaposi's sarcoma-associated herpesvirus) in
Brazil and Colorado. J oumal of Infectious Diseases, 178: 1488-1491.

20. Simpson GR, Schulz TF, Whitby D, Cook PM, Boshoff C, Rainbow L, Howard MR, Gao SJ , Bohenzky RA, Simmonds P, Lee C, de Ruiter A, Hatzakis A, Tedder RS, Weller IVD, Weiss RA \& Moore PS (1996). Prevalence of Kaposi's sarcoma associated herpesvirus infection measured by antibodies to recombinant capsid protein and latent immunofluorescence antigen. Lancet, 348: 1133-1138.

21. Purvis SF, Katangole-M bidde E, J ohnson J L, Leonard DGB, Byabazaire N, Luckey C, Schick HE, Wallis R, Elmets CA \& Giam CZ (1997). High incidence of Kaposi's sarcoma-associated herpesvirus and Epsteinbarr virus in tumor lesions and peripheral blood mononuclear cells from patients with Kaposi's sarcoma in Uganda. J ournal of Infectious Diseases, 175: 947-950.

22. Chatlynne LG \& Ablashi DV (1999). Seroepidemiology of Kaposi's sarcoma-associated herpesvirus (KSHV). Seminars in Cancer Biology (Review, Guest Editors Weiss $R$ and Boshoff C), 9: 175-185.

23. Sitas $F$, Carrara $H$, Beral V, Newton $R$, Reeves G, Bull $D$, J entsch $U$, PacellaNorman R, Bourboulia D, Whitby D, Boshoff C \& Weiss R (1999). Antibodies against human herpes virus 8 in black South African patients with cancer. New England J ournal of Medicine, 340: 18631871.

24. M in J \& Katzenstein DA (1999). Detection of Kaposi's sarcoma-associated herpesvirus in peripheral blood cells in human immunodeficiency virus infection: association with Kaposi's sarcoma, CD4 cell count, and HIV RNA levels. AIDS Research and Human Retroviruses, 15: 5155.

25. Smith MS, Bloomer C, Horvat R, Goldstein E, Casparian J M \& Chandran B (1997). Detection of human herpesvirus 8 DNA in Kaposi's sarcoma lesions and peripheral blood of human immunodeficiency virus-positive patients and correlation with serologic measurements. J ournal of Infectious Diseases, 176: 84-93.

26. Lefrère JJ, Meyohas $M C, M$ ariotti $M$, Meynard J L, Thauvin M \& Frottier J (1996). Detection of human herpesvirus 8 DNA sequences before the appearance of Kaposi's sarcoma in human immunodeficiency virus (HIV)-positive subjects with a known date of HIV seroconversion. J ournal of Infectious Diseases, 174: 283287. 